\begin{tabular}{|c|c|c|c|c|c|}
\hline & 3 & $9,12 \pm 0,20$ & $22,80 \pm 1,11$ & $46,58 \pm 1,55$ & $86,18 \pm 2,89$ \\
\cline { 2 - 6 } & 6 & $10,52 \pm 0,49$ & $23,59 \pm 1,09$ & $46,35 \pm 1,28$ & $86,06 \pm 3,50$ \\
\hline \multirow{3}{*}{ II } & 0 & $8,02 \pm 0,24$ & $20,25 \pm 0,79$ & $43,62 \pm 1,44$ & $82,99 \pm 2,73$ \\
\cline { 2 - 6 } & 3 & $9,95 \pm 0,45$ & $23,61 \pm 1,16$ & $46,09 \pm 2,10$ & $83,21 \pm 3,41$ \\
\hline \multirow{3}{*}{ III } & 6 & $10,60 \pm 0,20$ & $20,86 \pm 1,03$ & $46,95 \pm 2,11$ & $84,95 \pm 3,68$ \\
\cline { 2 - 6 } & 0 & $8,06 \pm 0,26$ & $20,18 \pm 1,05$ & $43,91 \pm 0,99$ & $82,75 \pm 2,13$ \\
\cline { 2 - 6 } & 3 & $9,56 \pm 0,23$ & $22,94 \pm 0,99$ & $46,32 \pm 1,26$ & $86,19 \pm 3,19$ \\
\hline
\end{tabular}

Nhận xét: Sau 18 tháng theo dõi độ ổn định ở điều kiện thực và 6 tháng ở điều kiện lão hoá cấp tốc, độ hòa tan của viên nang VER.HCl 120 mg giải phóng kéo dài thay đổi không đáng kể và vẫn đạt các yêu câu của USP 41.

\section{KẾT LUẬN}

Đã đánh giá được độ ổn định của chễ phẩm khi bảo quản 18 tháng ở điều kiện thực và 6 tháng ở điều kiện lão hóa cấp tốc, các chỉ tiêu chất lượng của viên nang VER.HCl $120 \mathrm{mg}$ giải phóng kéo dài (hình thức viên, hàm lượng, độ hòa tan) thay đổi không đáng kể và đạt yêu cầu tiêu chuẩn cơ sở của chế phẩm.

\section{TÀl LIỆ THAM KHẢO}

1. Bộ Y tế (2009), Dược thư quốc gia việt nam, Nhà xuất bản Y Học, tr. 979 - 981.

2. Martindale The Complete Drug Reference (2014), Thirty-eighth Edition, Pharmaceutical
Press, pp. 1522-1526.

3. BNF 73 (2017), Monograph: Verapamil hydrochloride, Pharmaceutical Press, London, pp. 155-156.

4. Truong Duc Manh, Vo Xuan Minh, Phan Thi Hoa, Nguyen Van Bach, Dinh Dinh Chinh (2021), Research on film coating formulation of sustained release pellets of verapamil hydrochloride, Tạp chí Y Dược học Quân sự, số 4, tr. $134-145$.

5. Food and drug Administration- USA (2003), Guidance for Industry: Q1A (R2) Stability Testing of New Drug Substances and Products.

6. ASEAN (2005), Guideline on Stability Study of Drug Product.

7. USP 41- NF 36 CD (2018), Monograph: verapamil hydrochloride extended-release tablets.

\title{
KHẢO SÁT SỰ HÀI LÒNG CỦA THÀNH VIÊN GIA ĐÌNH NGƯờI BÊNH ĐỐI VỚI NHÂN VIÊN Y TẾ THUộC BỆNH VIỆN BỆNH NHIỆT ĐỚI HẢI DƯO'NG NĂM 2019
}

\begin{abstract}
Phạm Thị Nhuyên***, Trần
\end{abstract}
\section{TÓM TẮT}

Mục tiêu: Đánh giá sự hài lòng của thành viên gia đình người bệnh (TVGĐ NB) với bác sĩ (BS), điêuu dưỡng (ĐD) và đối với các yếu tố khác thuộc Bệnh viện bệnh Nhiệt đới Hải Dương năm 2019. Đối tượng và phương pháp: Nghiên cứu mô tả cắt ngang 72 thành viên gia đình người bệnh điều trị tại Bệnh viện Nhiê̂t đới Hải Dương năm 2019. Kết qủa và kết luận: Mức độ hài lòng của TVGĐ NB với BS tại Bệnh viện bệnh Nhiệt đới Hải Dương: khám, giải thích về

*Trường Đại học KH và CN Hà Nội

**Trường Đại học Y tê Công cộng

***Trướng Đại học Thành Đông

Chịu trách nhiệm chính: Phạm Thị Nhuyên

Email: mhuyenmd@yahoo.com.vn

Ngày nhận bài: 2/10/2021

Ngày phản biện khoa học: 29/10/2021

Ngày duyệt bài: 12/11/2021
Nguyễn Thu Hà*, Trần Trọng Hải**, hư Nguyên***, Phí Thị Nguyệt Thanh***, Nguyễn Đức Sơn $* * *$, Nguyễn Thu Hà $* * *$ tình trạng bệnh, chẩn đoán, trực tiếp điều trị là 98,57\%. Mức độ hài lòng của TVGĐ NB với ĐD tai Bệnh viện bệnh Nhiệt đới Hải Dương, gồm: phổ biến những thông tin cân thiết khi vào Bệnh viện và trong quá trình điểu trị $(100 \%)$; Có lời nói, cử chỉ, thái độ thân thiện với người bệnh (NB) và TVGĐ NB $(98,61 \%) ;$ Tư vấn chế độ chăm sóc NB là $(100 \%)$; Tận tình giúp đỡ NB, TVGĐ̈, không gợi ý, đòi tiền quà̀ $(97,22 \%)$; Công khai thuốc $(95,83 \%)$ và hướng dẫn sử dụng thuốc (100\%). Mức độ hài lòng của TVGĐ NB với các yếu tố khác của Bệnh viện bệnh Nhiệt đới Hải Dương: Thủ tục hành chính nhanh gọn (100\%); Vệ sinh sạch sẽ $(94,45 \%)$; Cơ sở hạ tâng và trang thiết bị hiện đại $(65,28 \%)$.

Tư khóa: Sự hài lòng, thành viên gia đình, người bệnh, bác sĩ, điều dưỡng, bệnh nhiệt đới.

\section{SUMMARY \\ SATISFACTION SURVEY OF PATIENT \\ FAMILY MEMBERS AT HAI DUONG TROPICAL HOSPITAL IN 2019}


Objective: To assess the satisfaction of the patient's family members with doctors, nurses and other factors at Hai Duong Tropical Diseases Hospital in 2019. Subjects and methods: A cross-sectional descriptive study of 72 patient's family members, who were treated at Hai Duong Hospital for Tropical Diseases in 2019. Results and conclusion: Level of satisfaction of patient's family members with doctors: examines and explains the condition, diagnoses and directly treats $98.57 \%$. Level of satisfaction of patient's family members with nurses: Disseminate necessary information when entering the hospital and during treatment (100\%); Having words, gestures, and friendly attitude towards patients and patient's family members $(98.61 \%)$; Consulting patient care regime is $(100 \%)$; Dedicated to helping patients, patients without suggestions, asking for gifts (97.22\%); Publication of drugs (95.83\%) and instructions on drug use $(100 \%)$. Level of satisfaction with other factors of the Hospital: Quick administrative procedures (100\%); Hygiene (94.45\%); Modern infrastructure and equipment (65.28\%).

Keywords: Satisfaction, patient's family member, doctor, nurse, tropical disease.

\section{I. ĐĂT VẤN ĐỀ}

Y tế là một lĩnh vực dịch vụ, nên chỉ số hài lòng của người bệnh là tiêu chí dùng để đo lường sự đáp ứng của cơ sở y tế đối với những mong đợi của người bệnh. Sự kém hài lòng của người bểnh có quan hể nhân quả với khiếu kiện. Khiếu kiện làm mất khách hàng trung thành, phá võ mối quan hệ Thây thuốc - Người bệnh, làm giảm hình ảnh của ngành y tế, đồng thời làm gia tăng phí tổn y tế cho cả người bệnh và cơ sở y tế. Vì vậy, sự hài lòng của người bệnh là tài sản của bệnh viện (BV) trong nổ lực nâng cao chất lượng dịch vụ và duy trì người bệnh là khách hàng thẩn thiện [5]. Tuy nhiên, trong thực tế có nhiều NB có nhu cầu sử dụng dịch vụ nhưng họ bị mất hoăc giảm đi ý thức về hành vi của mình. Trong những trường hợp đó: TVGĐ NB đóng vai trò quan trọng trong việc đánh giá chất lượng dịch vụ chăm sóc của các cơ sở y tế, giúp các cơ sở này kịp thời khắc phục những tồn tại để hoàn thiện và phát triển.

Bệnh viện Bệnh Nhiệt đới Hải Dương tiền thân là Trung tầm phòng, chống HIV/AIDS Hải Dương đã trải qua 15 năm hoạt động. Hiện tại, có trên 80 giường bệnh và hơn 80 cán bộ nhẩn viên y tế. Nhiệm vụ của $B V$ : Chăm sóc cho khoảng 1500 NB nội, ngoại trú và hơn 10 nghìn lượt người đến thăm khám tại $B V$ mỗi năm. Đến nay, chưa có nghiên cứu đầy đủ nào về đánh giá chất lượng các dịch vụ y tế và chăm sóc NB. Vì vậy, chúng tôi tiến hành đề tài "Khảo sát sự hài lòng của thành viên gia đình người bệnh tại Bệnh viện Bệnh nhiệt đới Hải Dương năm 2019" là thực sự cần thiết. Mục tiêu nghiên cứu:

- Đánh giá sư hài lòng của thành viên gia đình người bệnh với bác sĩ và điều dưỡng tại Bệnh viện Bệnh nhiệt đới Hải Dương.

- Đánh giá sự hài lòng của thành viên gia đình người bệnh đối với các yếu tố khác tại Bệnh viện Bệnh nhiệt đới Hải Dương.

\section{II. ĐỐI TƯỢNG VÀ PHƯƠNG PHÁP NGHIÊN CứU}

1. Đối tượng nghiên cứu. 72 thành viên gia đình người bệnh; Mỗi người bệnh chọn một thành viên gia đình, người có tinh thần tỉnh táo và tự nguyện tham gia nghiên cứu.

2. Phương pháp nghiên cứu: Nghiên cứu mô tả cắt ngang

3. Địa điểm nghiên cứu: Bệnh viện Bệnh nhiệt đới Hải Dương

4. Thời gian nghiên cứu: năm 2019.

5. Yếu tố loại trừ: Những thành viên gia đình người bệnh không đủ nhận thức các câu hỏi, không tự nguyện tham gia nghiên cứu.

\section{KẾT QUẢ NGHIÊN CỨU}

\section{Mô tả đặc điểm của TVGĐ NB tại Bệnh} viện Bệnh nhiệt đới Hải Dương

Bảng 1. Phẩn bố theo giới của TVGĐ NB

\begin{tabular}{|c|c|c|}
\hline Giới & Số lượng & Tỷ lệ (\%) \\
\hline Nam & 47 & $\mathbf{6 5 , 2 8 \%}$ \\
\hline Nữ & 25 & $34,72 \%$ \\
\hline Tống & 72 & $100 \%$ \\
\hline
\end{tabular}

Nhận xét: Số lượng TVGĐ NB là nam chiếm đa số với tỷ lệ $65,28 \%$

Bảng 2. Phân bố theo tuôi của TVGĐ NB

\begin{tabular}{|c|c|c|}
\hline Nhóm tuối & Số lượng & Tỷ lệ (\%) \\
\hline$<30$ & 11 & 15,27 \\
\hline $30-50$ & 32 & $\mathbf{4 4 , 4 4 \%}$ \\
\hline$>50$ & 29 & $40,28 \%$ \\
\hline Tống & 72 & $\mathbf{1 0 0} \%$ \\
\hline
\end{tabular}

Nhân xét: - TVGĐ NB thuộc nhóm tuối dưới 30 chiếm tỷ lệ thấp nhất: $15,27 \%$

- TVGĐ NB thuộc nhóm tuổi 30 - 50 chiếm tỷ lệ cao nhất: 44,44\%

Bảng 3. Phân bố theo nghề nghiệp của TVGD NB

\begin{tabular}{|c|c|c|}
\hline Nghề nghiệp & Số lượng & Tỷ lệ (\%) \\
\hline Lao động trí óc & 13 & $18,07 \%$ \\
\hline Lao động chân tay & 55 & $\mathbf{7 6 , 3 8 \%}$ \\
\hline Người không lao động & 4 & $5,55 \%$ \\
\hline Tống & 72 & $100 \%$ \\
\hline
\end{tabular}

Nhận xét: Là người lao động chân tay chiếm cao nhất $(76,38 \%)$, thấp nhất là không lao động, $(5,55 \%)$

Bảng 4. Phân bố theo trình độ học vấn của TVGD NB

\begin{tabular}{|c|c|c|}
\hline Trình độ học vấn & Số lượng & Tỷ lệ (\%) \\
\hline THPT trở xuống & 61 & $\mathbf{8 4 , 7 2 \%}$ \\
\hline
\end{tabular}




\begin{tabular}{|c|c|c|}
\hline Trung cấp & 4 & $5,55 \%$ \\
\hline $\mathrm{CĐ}, \mathrm{DH}$ & 7 & $9,73 \%$ \\
\hline Tống & 72 & $\mathbf{1 0 0 \%}$ \\
\hline
\end{tabular}

Nhận xét: Hầu hết $(84,72 \%)$ có trình độ học vấn tữ THPT trở xuống, trình độ trung cấp là thấp nhất $(5,55 \%)$.

Bảng 5. Phân bố theo nơi ở của TVGD NB

\begin{tabular}{|c|c|c|}
\hline Nơi ớ & Số lượng & Tỷ lệ (\%) \\
\hline Miền núi & 12 & $\mathbf{8 0 , 5 5 \%}$ \\
\hline Nông thôn & 2 & $2,77 \%$ \\
\hline Thành phố & 58 & $16,68 \%$ \\
\hline Tống & $\mathbf{7 2}$ & $\mathbf{1 0 0 \%}$ \\
\hline
\end{tabular}

Nhân xét: Hầu hết $(80,55 \%)$ thuộc khu vực nông thôn, thấp nhất $(2,77 \%)$ thuộc miền núi.

2. Mức độ hài lòng của TVGĐ NB đối với BS và ĐD tại bệnh viện

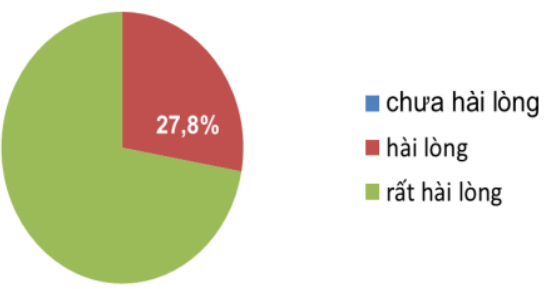

Biểu đồ 1. Điều dưỡng phổ biến những thông tin cần thiết khi vào viện rỗ ràng, dể hiêu

Nhận xét: $100 \%$ TVGĐ NB hài lòng và rất hài lòng về việc phổ biến những thông tin cần thiết khi vào viện rõ ràng, dễ hiểu.

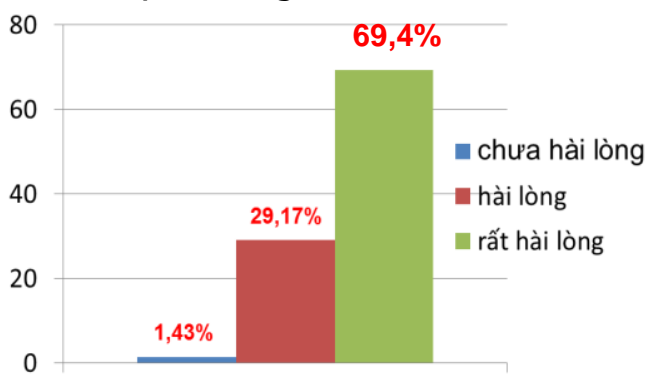

Biểu đồ 2. Bác sĩ giải thích về tình trạng bệnh, chân đoán, phương pháp điều trị

Nhận xét: Số lượng TVGĐ NB chưa hài lòng chiếm $1,43 \%$, rất hài lòng chiếm $69,4 \%$.

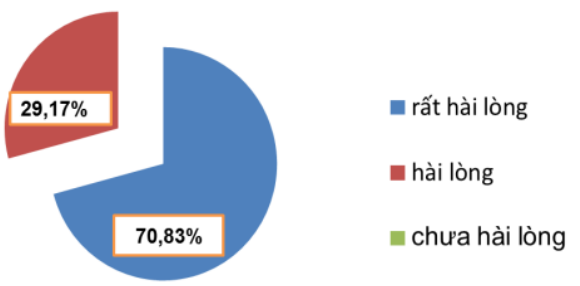

Biểu đồ 3. Điều dưỡng tiếp xúc, giải thích với NB trong quá trinh điều trị

Nhận xét: $100 \%$ TVGĐ NB hài lòng và rất hài lòng về việc tư vấn chế độ chăm sóc NB của ĐD.

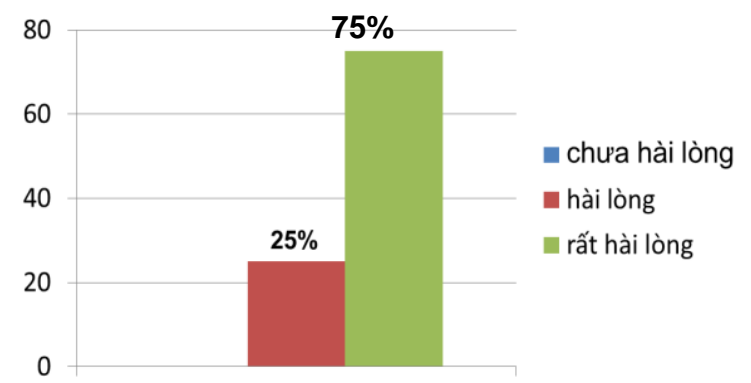

Biểu đồ 4. Điều dưỡng tư vấn chế độ chăm sóc NB Cho TVGD.

Nhận xét: 100\% số lượng TVGĐ NB hài lòng và rất hài lòng với việc $Đ D$ giải thích, động viên NB trước, trong và sau khi làm thủ thuật

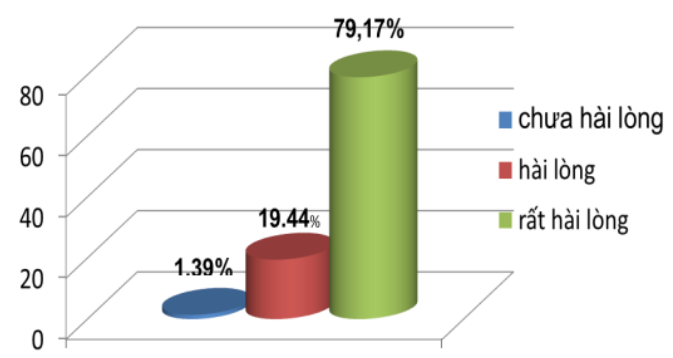

Biêu đồ 5. Điều dưỡng có lời nói, cử chỉ, thái độ thân thiện với $N B$ và TVGD

Nhận xét: Hầu hết $(79,17 \%)$ TVGĐ NB rất hài lòng, chưa hài lòng có tỷ lệ rất thấp (1,39\%).

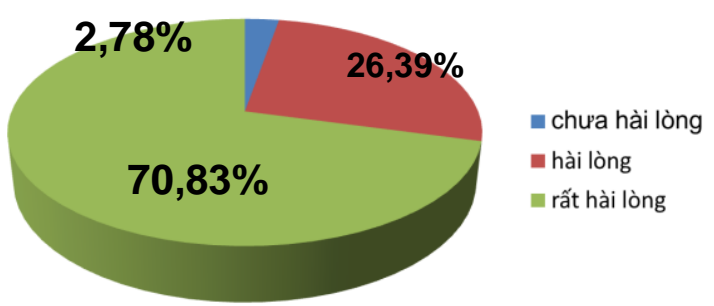

Biểu đồ 6. Điều dưỡng tận tình giúp đỡ NB, TVGD và không gợi ý đòi biêu tiền, quà

Nhận xét: Hâu hết TVGĐ NB rất hài lòng $(70,83 \%)$ và hài lòng $(26,39 \%)$; Có rất ít $(2,78 \%)$ trong số họ là không hài lòng.

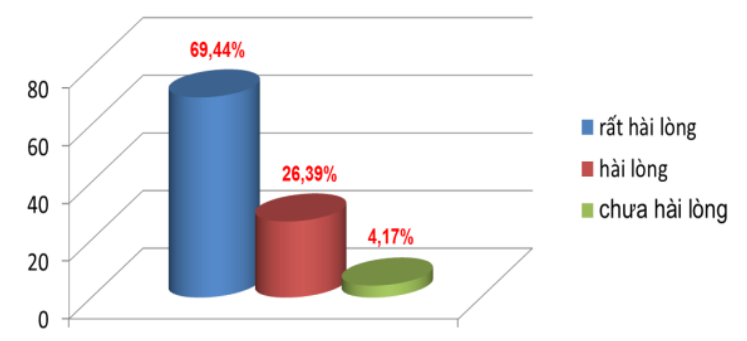

Biểu đồ 7. Điều dưỡng công khai về thuốc 
Nhân xét: Đa số TVGĐ NB rất hài lòng $(69,44 \%)$; Có rất ít $(4,17 \%)$ trong số họ là không hài lòng về việc người điều dưỡng công khai về thuốc.

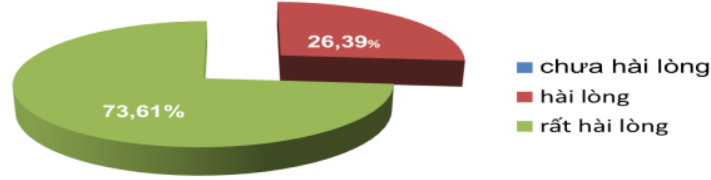

Biểu đồ 8. Điều dưỡng hướng dẫn sử dụng thuốc

Nhân xét: $100 \%$ tổng số TVGĐ NB hài lòng và rất hài lòng với việc điều dưỡng hướng dẫn sử dụng thuốc

3. Đánh giá của TVGĐ NB về các yếu tố khác của Bệnh viện

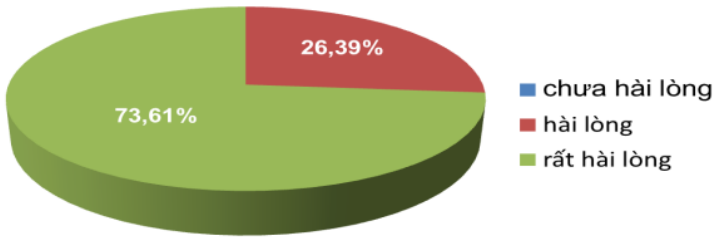

Biêu đồ 9. Các thủ tục hành chính nhanh gọn Nhận xét: $100 \%$ số TVGĐ NB hài lòng và rất hài lòng với việc các thủ tục hành chính nhanh gọn.

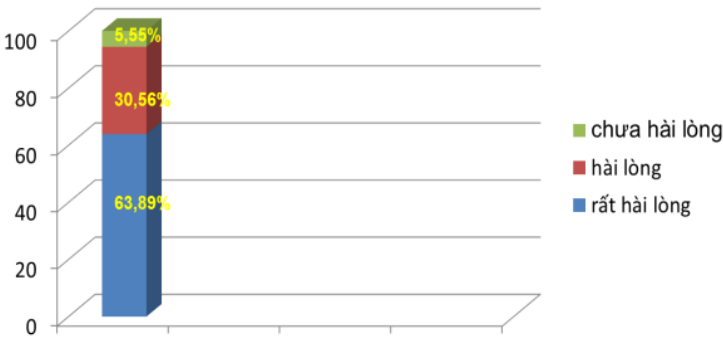

Biểu đồ 10. Đánh giá của TVGĐ NB về vệ sinh của bệnh viện

Nhân xét: Tỷ lê rất thấp $(5,55 \%)$ TVGĐ NB chưa hài lòng về vệ sinh của bệnh viện.

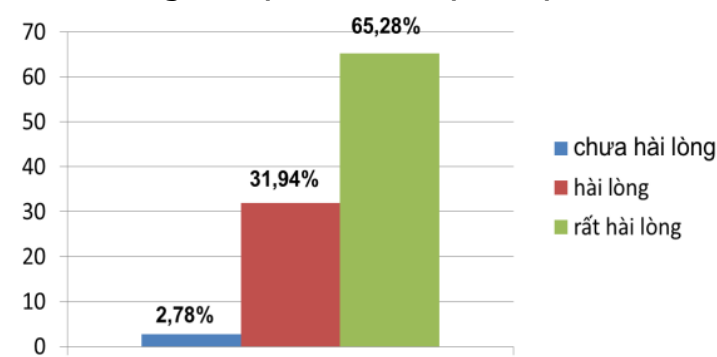

Biểu đồ 11. Đánh giá của TVGĐ NB về cơ sở hạ tầng, trang thiêt bi.

Nhận xét: Hầu hết TVGĐ NB rất hài lòng $(65,28 \%)$ và hài lòng $(31,94 \%)$; Có rất ít $(2,78 \%)$ là chưa hài lòng về cơ sở hạ tầng, trang thiết bị của bệnh viện.

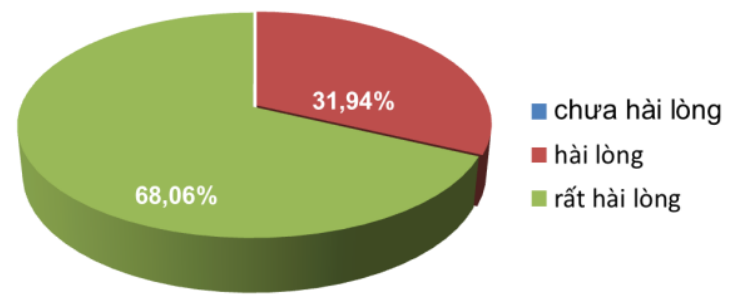

Biểu đồ 12. Đánh giá của TVGĐ NB về tiến triển của NB khi điều trị tại Bệnh viện

Nhận xét: $100 \%$ số lượng TVGĐ NB hài lòng với tiến triển của NB khi điều trị tại Bệnh viện

\section{BÀN LUÂN}

1. Mức độ hài lòng của TVGĐ BN đối với Bác sĩ tại Bệnh viện

Mức độ hài lòng của TVGĐ BN đối với bác sĩ tại Bênh viênn, về viêc: BS giải thích về tình trạng bệnh, chẩn đoán và phương pháp điều trị đạt tới $98,57 \%$ trong đó $69,4 \%$ là rất hài lòng, $29,17 \%$ là hài lòng. Tuy nhiên vẫn còn một tỷ lế nhỏ $(1,43 \%)$ TVGĐ NB cho rằng họ chưa thấy BS giải thích một cách cặn kẽ về tình trạng bệnh của người thân. Kết quả này cao hơn nghiên cứu của Nguyễn Huy Xuân (2013) [8].

2. Mức độ hài lòng của TVGĐ $B N$ đối với Điều dưỡng tại Bệnh viện rất cao, cụ thể:

* $100 \%$ TVGĐ NB rất hài lòng và hài lòng với việc $Đ D$ phổ biến những thông tin cần thiết khi vào bênh viện. TVGĐ NB cho rằng $Đ D$ cần tiếp tục phát huy điều đó. Kết quả này cao hơn nghiên cứu của Phạm Thị Vân (2009) "Khảo sát thực trạng giao tiếp và ứng xử của điều dưỡng tại Bênh viện đa khoa tỉnh Hà Giang năm 2009 [6] và Phạm Thị Thu Thảo (2003) [5].

*100\% TVGĐ NB hài lòng với viêc DD giải thích tiếp xúc với NB trong quá trình điểu trị. Điều này được lý giải rằng các $\mathrm{DD}$ thường xuyên được tập huấn các công tác chăm sóc NB, nhất là NB có rổi loạn về ý thức, sa sút trí tuệ,... Do vậy TVGĐ NB rất an tâm khi để người thân của mình điều trị tại bênh viên. Kết quả này cao hơn nghiên cứu của Đào Thị Vui và cộng sự (2004), [7].

*Tỷ lê TVGĐ NB hài lòng với giao tiếp của $\mathrm{DD}$ là $98,61 \%$ với sự cảm thông, chia sẻ, có lời nói và cử chỉ thân thiện với bênh nhân. Kết quả này cao hơn nghiên cứu của Đỗ Mạnh Hùng và CS (2013) tại Bệnh viện Nhi trung ương"[2] là 67,3\%. 
1,39\% TVGĐ NB còn lại trong nghiên cứu của chúng tôi cho rằng một số $D$ còn có thái độ thờ o, lạnh lùng với họ và người thân của họ.

*100\% TVGĐ NB nhận định rằng ĐD tận tình giúp đõ NB, không có biểu hiện ban ơn, gợi ý tiền quà. Cùng với đó họ cũng cho rằng $Đ \mathrm{D}$ luôn tư vấn dinh dưỡng và chế độ chăm sóc người bệnh cho TVGĐ NB. Yếu tố đó được TVGĐ NB ghi nhận và mong muốn ĐD phát huy.

*Đối với việc công khai thuốc và hướng dẫn sử dụng thuốc, trên 95\% TVGĐ NB nhận thấy họ được ĐD hướng dẫn đầy đủ và chi tiết. Nghiên cứu này cao hơn kết quả nghiên cứu của Lê Thị Thúy Hằng (2013) là 81,67\%. [1]

3. Mức độ hài lòng của TVGĐ BN đối với các yếu tố khác của bệnh viện, gồm:

*97,22\% TVGĐ NB hài lòng với cơ sở hạ tầng, trang thiết bị của Bệnh viện, chỉ có một tỷ lệ nhỏ $(2,78 \%)$ TVGĐ NB cho rằng Bệnh viện cần trang bị thêm nhiêu máy móc kỹ thuật cao để việc chẩn đoán bệnh được nhanh và tiện lợi hơn.

*Có 94,5\% tỷ lệ TVGĐ NB hài lòng với vệ sinh tại Bệnh viện. Điều này được lý giải rằng đây là cơ sở chuyên khoa có đặc thù điều trị cho những bệnh nhân HIV/AIDS và bệnh Truyền nhiễm nên vệ sinh hết sức sạch sẽ và có không gian thoáng mát tạo môi trường tốt giúp NB mau hồi phục. Kết quả này cũng tương đương với nghiên cứu của Nguyễn Văn Nam (2011) tại Bệnh viện Bệnh nhiệt đới Trung ương năm 2011 là 95\% [4]

* $100 \%$ TVGĐ NB cho rằng các thủ tục hành chính được tiến hành một cách nhanh gọn không gây phiền hà. Đa số NB điều trị tại Bệnh viện thuộc đối tượng có bảo hiểm y tế nên việc làm thủ tục hành chính cũng mất ít thời gian hơn do có sự luân chuyển giữa các tuyến.

*100\%, TVGD NB hài lòng với sự tiến triển của người thân, trong đó gồm: rất hài lòng $(68,06 \%)$ và hài lòng $(31,94 \%)$. Bác sĩ luôn cập nhật những kiến thức để nâng cao trình độ chuyên môn về chăm sóc và điều trị NB một cách hiệu quả. Nghiên cứu này tương đương với kết quả nghiên cứu của Nguyền Kim Liên (2016) tại khoa phục hồi chức năng Bệnh viện trường Đại học Kỹ thuật $Y$ tế Hải Dương [3] với sự hài lòng của NB là $31,1 \%$ và rất hài lòng là $68,9 \%$

\section{KẾT LUÂN}

1. Mức độ hài lòng của TVGĐ NB với Bác sĩ của bệnh viện, gồm: giải thích về tình trạng bệnh, chẩn đoán, phương pháp điều trị là $98,57 \%$

2. Mức độ hài lòng của TVGĐ NB với Điều dưỡng của bệnh viện, gồm: Phổ biến những thông tin cần thiết khi vào viện và trong quá trình điều trị (100\%); Tiếp xúc, giải thích với NB, TVGD NB trong quá trình điều trị như có lời nói, cử chỉ, thái độ thân thiện với NB, TVGĐ NB $(98,61 \%) ;$ Tư vấn chế độ chăm sóc người bệnh $(100 \%) ;$ ĐD tận tình giúp đơ NB, NNBN, khổng có biểu hiện ban ơn, gợi ý tiền quà $(97,22 \%)$; Công khai thuốc $(95,83 \%)$ và hướng dẫn sử dụng thuốc (100\%)

3. Mức độ hài lòng của TVGĐ NB với các yếu tố khác của Bệnh viện, về:

Các thủ tục hành chính nhanh gọn (100\%); Vấn đề vệ sinh của Bệnh viện (94,45\%) và cơ sở hạ tầng, trang thiết bị của Bệnh viện $(65,28 \%)$.

\section{KIẾN NGH!}

1. Tiếp tục duy trì và nâng cao chất lượng khám bệnh chưa bệnh, phục vụ NB để đáp ứng sự hài lòng của NNBN, NB.

2. Cán bộ y tế phải chú trọng đến vấn đề giải đáp những thắc mắc cho NB, TVGĐ về thuốc, phương pháp điều trị, thủ thuật điều trị...

3. Tiếp tục đâu tư nâng cẩp trang thiết bị, cơ sở vật chất hiện đại, phù hợp đáp ứng được nhu cầu khám chữa bệnh, điều trị nội trú của NB.

\section{TÀI LIẸU THAM KHẢO}

1. Lê Thị Thúy Hằng (2013), "Sự hài lòng của người bệnh, người nhà bệnh nhân với ĐD và $\mathrm{BS}$ tại khoa khám bếnh Bệnh viên Tuế Tĩnh năm 2013" Đề tài tốt nghiệp cử nhẩn hệ VLVH khoa Điều dưỡng, trường Đại học Thăng Long (năm 2013),tr.35.

2. Đố Mạnh Hùng và CS (2013), " Sự hài lòng của khách hàng về thái độ phục vụ bệnh nhân của Điều dưỡng viên tại Bệnh viện Nhi trung ương"

3. Nguyển Kim Liên (2016), "Khảo sát mức độ hài lòng của người bệnh tại khoa phục hồi chức năng Bệnh viện trường Đại học Kỹ thuật $Y$ tế Hải Dương tháng 4,5,6 năm 2016" Khóa luận tốt nghiệp Cữ nhân phục hồi chức năng trường ĐHKTYTं Hải Dương (năm 2016),tr.34

4. Nguyến Văn Nam (2011), "Đánh giá sự hài lòng của người bệnh trầm cảm điều trị nội trú tại Bệnh viện Bệnh nhiệt đới Trung ương năm 2011"

5. Phạm Thị Thu Thảo (2003), "Khảo sát sự hài lòng của người nhà bệnh nhân đối với giao tiếp của điều dưỡng viên tại Bệnh viện Bạch Mai", Tạp chí y học thực hành (870), số 5/2013

6. Pham Thi Vân (2009), "Khảo sát thực trang giao tiếp và ứng xử của điều dưỡng tại Bệnh viện đa khoa tỉnh Hà Giang từ tháng 4/2009 đến tháng $8 / 2009^{\prime \prime}$

7. Đào Thị Vui và cộng sự (2004), "Báo cáo về thực trạng giao tiếp của điêu dưỡng tại Bệnh viện nhi Trung ương", tr.18-21

8. Nguyễn Huy Xuân (2013), " Phân tích hoạt động cung ứng thuốc tại Bệnh viện tâm thần Hải Dương" NXB Bộ y tế trướng ĐH Dược Hà Nội. 